Normal PolyQ

Repeat

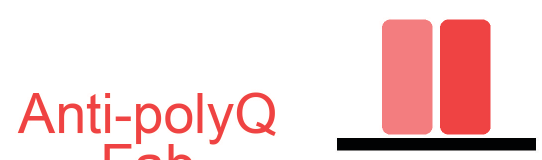

Fab

Anti-polyQ

$\lg G$
Expanded PolyQ

Repeat
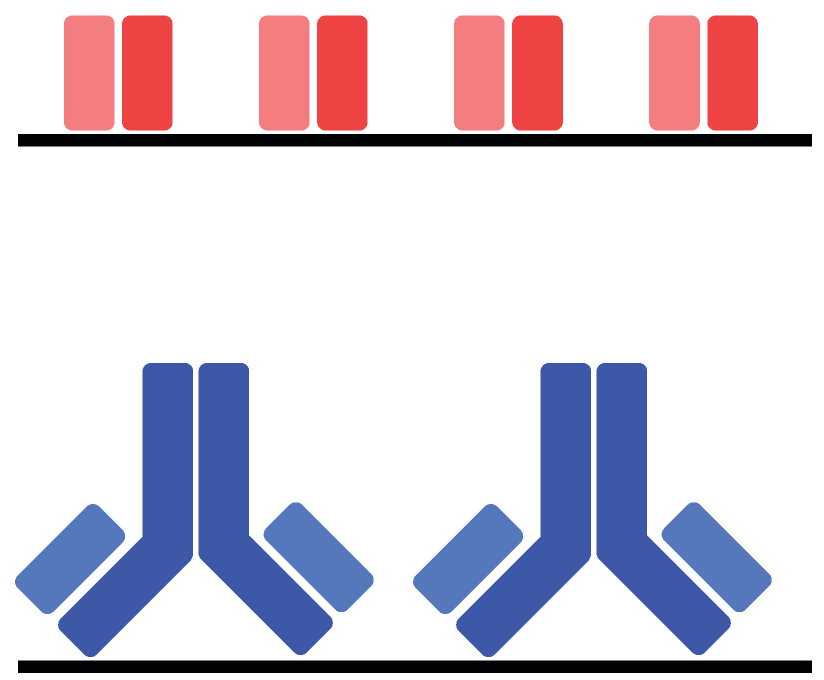


\section{Anti-polyQ antibodies recognize a short polyQ stretch in both normal and mutant huntingtin exon 1}

Gwen E. Owens ${ }^{a, b}$, Danielle M. New ${ }^{a}$, Anthony P. West, Jr. ${ }^{a}$, Pamela J. Bjorkman ${ }^{a, c,}$

a Division of Biology and Biological Engineering 114-96, California Institute of Technology, 1200 East California Boulevard, Pasadena, CA 91125, USA

${ }^{\mathrm{b}}$ Graduate Option in Biochemistry and Molecular Biophysics, California Institute of Technology, 1200 East California Boulevard, Pasadena, CA 91125, USA

${ }^{c}$ Howard Hughes Medical Institute

* Correspondence to Pamela Bjorkman: bjorkman@caltech.edu, phone (626) 395-8351, fax (626) 792-3683, 1200 East California Boulevard, MC 114-96, Pasadena, CA 91125, USA

\section{ABSTRACT}

Huntington's disease (HD) is caused by expansion of a polyglutamine (polyQ) repeat in the huntingtin protein. A structural basis for the apparent transition between normal and disease-causing expanded polyQ repeats of huntingtin is unknown. The 'linear lattice' model proposed random-coil structures for both normal and expanded polyQ in the preaggregation state. Consistent with this model, the affinity and stoichiometry of the anti-polyQ antibody MW1 increased with the number of glutamines. An opposing 'structural toxic threshold' model proposed a conformational change above the pathogenic polyQ threshold resulting in a specific toxic conformation for expanded polyQ. Support for this model was provided by the anti-polyQ antibody 3B5H10, which was reported to specifically recognize a distinct pathologic 
conformation of soluble expanded polyQ. To distinguish between these models, we directly compared binding of $\mathrm{MW} 1$ and $3 \mathrm{~B} 5 \mathrm{H} 10$ to normal and expanded polyQ repeats within huntingtin exon 1 fusion proteins. We found similar binding characteristics for both antibodies. First, both antibodies bound to normal, as well as expanded, polyQ in huntingtin exon 1 fusion proteins. Second, an expanded polyQ tract contained multiple epitopes for antigen-binding fragments (Fabs) of both antibodies, demonstrating that 3B5H10 does not recognize a single epitope specific to expanded polyQ. Finally, small angle X-ray scattering and dynamic light scattering revealed similar binding modes for MW1 and 3B5H10 Fab-huntingtin exon 1 complexes. Together, these results support the linear lattice model for polyQ binding proteins, suggesting that the hypothesized pathologic conformation of soluble expanded polyQ is not a valid target for drug design.

\section{KEYWORDS}

Equilibrium gel filtration; Huntington's disease; linear lattice; polyglutamine; small angle X-ray scattering

\section{ABBREVIATIONS}

AUC, analytical ultracentrifugation; CDR, complementarity determining region; Fab, antigen-binding fragment; HC, heavy chain; HD, Huntington's disease; LC, light chain; MALS, multiangle light scattering; poly $Q$, polyglutamine; $R_{\mathrm{g}}$, radius of gyration; $R_{h}$, hydrodynamic radius; SAXS, small angle X-ray scattering; SEC, size-exclusion chromatography; SPR, surface

plasmon resonance; SSRL, Stanford Synchrotron Radiation Lightsource; TRX, thioredoxin; $V_{H}$, heavy chain variable domain; $V_{\mathrm{L}}$, light chain variable domain

\section{INTRODUCTION}

Huntington's disease (HD) is a fatal neurodegenerative disorder characterized clinically 
by psychiatric symptoms, cognitive decline, and uncontrolled movements [1]. HD is caused by expansion of a CAG repeat within exon 1 of $H T T$ (previously $H D$ ) that encodes an expanded polyglutamine (polyQ) tract in the $\mathrm{N}$-terminal portion of the huntingtin protein. A pathologic threshold exists for HD, in which HD is fully penetrant in patients with 42 or more glutamines in the huntingtin protein, but no disease is found in individuals with 36 or fewer glutamines, while huntingtin with 37 to 41 glutamines exhibits reduced HD penetrance [2]. Although a structural basis for an apparent normal-disease threshold is unknown, several hypotheses exist for the conformation of monomeric, soluble polyQ in normal and expanded huntingtin protein.

The 'linear lattice' hypothesis proposed that polyQ retains a random-coil structure for both normal and expanded polyQ in the preaggregation state. In this model, the increase in number of binding epitopes in expanded polyQ compared with normal polyQ results in avidity effects that cause higher apparent affinities for bivalent proteins such as antibodies [3]. This could induce altered binding interactions with other cellular proteins or other polyQ repeats, leading to neuronal toxicity. Consistent with this model, the affinity of the anti-polyQ antibody MW1 to huntingtin amino terminal protein encoded by exon 1 (hereafter called huntingtin exon 1 protein) increased in a polyQ-length dependent manner, and binding of multiple antigen-binding fragments (Fabs) of MW1 to expanded polyQ tracts was observed. In addition, huntingtin exon 1 protein with 16 - 46 glutamines exhibited a random coil conformation in solution, and no evidence was found for a global conformation change above 37 glutamines [3, 4]. Surface plasmon resonance (SPR) and analytical ultracentrifugation (AUC) studies also demonstrated that multiple MW1 Fabs bound to expanded polyQ tracts [3]. The X-ray crystal structure of a $\mathrm{GQ}_{10} \mathrm{G}$ peptide bound to the variable regions of $\mathrm{MW} 1$ revealed that a short polyQ tract adopted an extended structure in a diagonal binding groove across the antigen-binding site of MW1 [4]. Additional binding studies using the anti-polyQ antibody $1 \mathrm{C} 2$ [5] showed that $1 \mathrm{C} 2$ also exhibited preferential binding to expanded polyQ due to avidity effects, and this preferential binding was not due to a mutant huntingtin-specific toxic structure recognized by $1 \mathrm{C} 2$ [6]. 
In contrast, the 'structural toxic threshold' model proposed that a conformational transition occurs in polyQ repeats that are longer than the pathological threshold, which results in a specific toxic conformation for monomeric expanded polyQ that could potentially be recognized by antibodies [7]. According to this model, the postulated pathologic conformation could be directly toxic or it could alter interactions between mutant huntingtin and its binding partners; in either case, the pathologic conformation could be targeted for drug design. Support for this model was provided by studies of the anti-polyQ antibody $3 \mathrm{~B} 5 \mathrm{H} 10$, which was reported to recognize a single epitope representing a distinct pathologic conformation of soluble expanded polyQ $[8,9]$. In these studies, 3B5H10 IgG preferentially bound to expanded polyQ, and a two-stranded $\beta$-hairpin conformation of polyQ was modeled into the predicted polyQbinding groove of the 3B5H10 Fab structure [9]. Support for this model was provided by a gel filtration assay of $3 \mathrm{~B} 5 \mathrm{H} 10 \mathrm{Fab}$ binding to a $\mathrm{Q}_{39}$-containing huntingtin exon 1 fusion (HD-39Q) protein, which was interpreted to demonstrate a binding stoichiometry of 1:1 3B5H10 Fab:HD$39 \mathrm{Q}$ [8]. These results were suggested to indicate that $3 \mathrm{~B} 5 \mathrm{H} 10$ binds to a single structured polyQ epitope only present in expanded polyQ, as per the structural toxic threshold hypothesis. Modeling of small-angle X-ray scattering (SAXS) data was interpreted as showing that $3 \mathrm{~B} 5 \mathrm{H} 10$ Fab bound to HD-39Q in a 2:2 3B5H10 Fab:HD-39Q complex in which each 3B5H10 Fab recognized one subunit of an HD-39Q dimer through binding to a two-stranded $\beta$-hairpin conformation of polyQ [9]. Contradictory evidence was provided by a recent report demonstrating that pull-down assays and surface plasmon resonance (SPR) studies showed that $3 \mathrm{~B} 5 \mathrm{H} 10 \mathrm{lgG}$, like MW1 and $1 \mathrm{C} 2 \mathrm{lgGs}$, could bind to short polyQ tracts, as expected given the high sequence and structural similarities between the three antibodies [6].

Here we compared the recognition properties of the anti-polyQ monoclonal antibodies MW1 and 3B5H10 by studying their interactions with a polyQ-containing fragment of huntingtin. Using expressed and purified huntingtin exon 1-thioredoxin (TRX) fusion proteins containing 16 to 46 glutamines (HD-16Q, HD-25Q, HD-39Q, HD-46Q) (Fig. 1a), we directly compared the 
interactions between soluble huntingtin and these anti-polyQ antibodies using biochemical and biophysical analysis techniques. We found that both MW1 and 3B5H10 antibodies exhibited similar binding properties, with neither providing evidence for a toxic conformation of expanded polyQ. These results argue against strategies designed to target a novel toxic conformation of soluble mutant huntingtin exon 1 protein in the preaggregation state.

\section{RESULTS}

\section{Both MW1 and 3B5H10 antibodies bind to normal and expanded polyQ within huntingtin exon 1 proteins}

Western blots were used to evaluate the binding of $3 \mathrm{~B} 5 \mathrm{H} 10$ and MW1 IgGs to equimolar amounts of huntingtin exon 1-TRX fusion proteins and to the TRX tag alone (Fig. 1b). If 3B5H10 recognizes a toxic conformation present only in expanded polyQ, then unlike MW1, it should not bind to short polyQ repeats. In contrast with some previous results [9], but consistent with other results $[10,11]$, we found that both $\mathrm{MW} 1$ and $3 \mathrm{~B} 5 \mathrm{H} 10 \mathrm{lgGs}$ bound in a similar manner to huntingtin exon 1 fusion proteins, each capable of binding to huntingtin exon 1 proteins containing both normal and expanded polyQ repeats. Both IgGs bound to huntingtin exon 1 proteins in a polyQ-dependent manner, with a progressively more intense signal with increased polyQ length. Based on these results, and previous western blots demonstrating the ability of $3 \mathrm{~B} 5 \mathrm{H} 10$ to bind to GST-polyQ with both short and long polyQ repeats [6], we conclude that both antibodies recognize a similar polyQ epitope that is present in both normal and expanded huntingtin exon 1 proteins.

In order to determine how it is possible to obtain results appearing to indicate that $3 \mathrm{~B} 5 \mathrm{H} 10$ binds only to expanded polyQ, we examined binding of $3 \mathrm{~B} 5 \mathrm{H} 10$ and $\mathrm{MW} 1$ as a function of concentration to huntingtin exon 1 proteins with different polyQ repeat lengths. Dot blots of serial dilutions of huntingtin exon 1 proteins demonstrated that both $3 \mathrm{~B} 5 \mathrm{H} 10$ and $\mathrm{MW} 1 \mathrm{IgGs}$ bound to huntingtin exon 1 proteins in a length- and concentration-dependent manner (Fig. 1c). 
At higher concentrations of huntingtin exon 1 protein, both IgGs recognized huntingtin exon 1 constructs with polyQ tracts ranging from $Q_{16}$ to $Q_{46}$. However, at lower concentrations of huntingtin exon 1 protein, a more intense signal was observed for the huntingtin exon 1 construct with the longest polyQ repeat (HD-46Q) compared to the construct with the shortest polyQ repeat (HD-16Q) (Fig. S1b,c). Due to the length- and concentration-dependent binding, conditions can be found in which MW1 or 3B5H10 lgG appeared to only bind expanded polyQ, thus explaining previously-reported results that 3B5H10 only recognizes huntingtin with expanded polyQ [9]. However, for both antibodies, the binding dependence on polyQ length was progressive, without a distinct threshold at polyQ lengths $>37 Q$. Thus, avidity effects resulted in bivalent IgG versions of 3B5H10 and MW1 showing preferential binding to expanded polyQ, as predicted by the linear lattice model for antibody interactions with polyQ repeats [3, 12].

\section{Huntingtin exon 1 proteins are monomeric in solution}

During purification of huntingtin exon 1 fusion proteins, we observed anomalous migration by gel filtration chromatography such that huntingtin exon 1 fusion proteins appeared to migrate as higher molecular weight proteins (e.g., dimers) when compared with molecular weight standards of globular proteins. To determine the oligomeric state of the huntingtin exon 1 fusion proteins, we used a combination of size-exclusion chromatography (SEC) with in-line multiangle light scattering (SEC-MALS), a technique that can be used to determine the absolute molecular mass of a protein or complex independent of shape and model [13]. To evaluate the methodology, we first analyzed 3B5H10 Fab alone, which migrated as a single monodisperse peak whose derived molecular mass closely matched the mass calculated from the amino acid sequence (Fig. 2; Table 1). HD-16Q and HD-39Q fusion proteins also migrated as monodisperse peaks, and their calculated molecular masses corresponded to monomers in each case (Table 1). Thus the anomalous migration of each huntingtin exon 1 protein in positions expected for a dimeric version of a globular protein of the same molecular mass 
results from slower migration due to an elongated structure rather than from dimerization. In particular, no evidence was found for dimer formation for HD-39Q as predicted in a previous study involving the modeling of small-angle X-ray scattering (SAXS) data [9].

\section{Non-equilibrium gel filtration chromatography analyses yield inconsistent apparent binding stoichiometries}

We next replicated published non-equilibrium gel filtration chromatography experiments that were conducted to determine the stoichiometry of binding between 3B5H10 Fab and huntingtin exon 1 protein with an expanded polyQ repeat using the same proteins: 3B5H10 Fab and HD-39Q [8]. By varying the ratio of 3B5H10 Fab to HD-39Q, we determined the ratio where the least amount of excess Fab or excess HD-39Q was detected, the method previously used to report a 1:1 3B5H10:HD-39Q binding stoichiometry [8]. Similar to the published results, we found that unbound 3B5H10 Fab was present at ratios greater than 1:13B5H10 Fab:HD-39Q, unbound HD-39Q was present at ratios less than $1: 1$, and that the ratio where the least amount excess of Fab or excess HD-39Q could be detected was 1:1 (Fig. 3a). As a control, we repeated the non-equilibrium gel filtration stoichiometry experiment to evaluate the binding behavior of MW1 Fab and HD-39Q (Fig. 3b), which was previously shown to form a complex with a greater than 1:1 stoichiometry [3]. Under non-equilibrium conditions, the stoichiometry of MW1 Fab:HD$39 \mathrm{Q}$ appeared to be less than 1:1. Thus it appeared that non-equilibrium gel filtration could not be reliably used to derive an accurate binding stoichiometry for an anti-polyQ Fab binding to huntingtin exon 1 fusion proteins with expanded polyQ.

However, we noted that with increasing molar ratios of 3B5H10 Fab:HD-39Q, the complex peak eluted earlier on the gel filtration column, suggesting that a complex larger than $1: 1$ was forming at the same time as $3 \mathrm{~B} 5 \mathrm{H} 10$ Fab was dissociating from HD-39Q. Due to the anomalous migration of HD-39Q compared with globular proteins using gel filtration chromatography (see above), the molecular mass of the 3B5H10 Fab:HD-39Q complex peak 
could not accurately be estimated based on gel filtration migration. Using SEC-MALS, we found that the complex of 3B5H10 Fab and HD-39Q was polydisperse, and the molecular mass of the peak fraction corresponded to a complex composed of greater than a 1:1, but less than a 2:1, ratio of 3B5H10 Fab:HD-39Q (Table 1), demonstrating that dissociation of the complex occurred during the experiment. In contrast, the complex of 3B5H10 Fab and HD-16Q migrated as a monodisperse peak, and the calculated molecular mass for a 1:1 3B5H10 Fab:HD-16Q stoichiometric ratio was in close agreement with the molecular mass obtained by SEC-MALS (Table 1).

Taken together, the results for these experiments suggested that binding stoichiometries for MW1 and 3B5H10 Fabs binding to huntingtin exon 1 proteins as determined by nonequilibrium gel filtration are incorrect. This is likely because protein complexes that dissociate during this procedure are unable to rebind due to separation by the gel filtration column. Therefore depending on the binding kinetics and the amount of separation between anti-polyQ Fabs and huntingtin exon 1 proteins on the gel filtration column, the binding stoichiometries determined by non-equilibrium gel filtration techniques may be artificially low, as has been found in other protein-protein interaction systems evaluated by this technique $[14,15]$.

\section{Expanded polyQ tracts within huntingtin exon 1 proteins contain multiple epitopes for the antigen-binding fragments (Fabs) of MW1 and 3B5H10}

To determine an accurate stoichiometry of binding between HD-39Q and the Fabs of 3B5H10 and MW1, we used equilibrium gel filtration [16]. In this technique, a chromatography column is run with an equilibration buffer containing one of the binding partners (e.g., protein A). Different ratios of the binding partners (e.g., protein A and protein B) are then injected onto the column. When the amount of additional protein $A$ injected is less than that required for formation of a complex, a trough will form at the position that protein A migrates. If the amount of additional protein $\mathrm{A}$ injected is in excess for complex formation, a peak is observed at the 
position that protein A migrates. When the amount of additional protein $A$ injected is at the amount required for complex formation, a flat baseline is observed at the position that protein $\mathrm{A}$ migrates. However, unless the protein concentration in the equilibration buffer is much greater than the affinity of the protein-protein complex, the ratio of protein $A$ to protein $B$ at which a flat baseline is observed will not be an integer, in which case the correct stoichiometry can be obtained by rounding up to the next integer [14] or by Scatchard analysis [15]. Previous measurements demonstrated a higher polyQ binding affinity for 3B5H10 Fab than for MW1 Fab: $K_{\mathrm{D}}=1.0 \mu \mathrm{M}$ for $3 \mathrm{~B} 5 \mathrm{H} 10 \mathrm{Fab}$ binding to $\mathrm{a} \mathrm{Q}_{22}$ or $\mathrm{Q}_{41}$ peptide [6] versus $K_{\mathrm{D}}=2.2 \mu \mathrm{M}$ for MW1 Fab binding to HD-39Q [3]. Therefore we used higher concentrations of MW1 Fab (1-10 $\mu \mathrm{M})$ than $3 \mathrm{~B} 5 \mathrm{H} 10 \mathrm{Fab}(0.5-5 \mu \mathrm{M})$ in these experiments.

Complexes containing different ratios of Fab and HD-39Q were incubated together and injected onto a gel filtration column equilibrated with the appropriate Fab. A series of experiments with different concentrations of 3B5H10 Fab in the equilibration buffer were performed. For example, for $5 \mu \mathrm{M}$ of 3B5H10 Fab in the equilibration buffer, the stoichiometry at which no peak or trough was observed was $~ 2.6: 1$ (Fig. 4a). Analysis with MW1 Fab yielded similar results, with the MW1 Fab:HD-39Q stoichiometry approaching 3:1 (Fig. 4b). Therefore for both antibodies, the stoichiometry of binding was determined as 3:1 Fab:HD-39Q.

\section{Dynamic light scattering (DLS) revealed similar sizes for complexes of MW1 and 3B5H10} Fabs with huntingtin exon 1 proteins

To further investigate complexes of anti-polyQ Fabs bound to huntingtin exon 1 proteins, we used dynamic light scattering (DLS) to compare hydrodynamic radii $\left(R_{h}\right)$ of $3 B 5 \mathrm{H} 10$ and MW1 Fabs alone, HD-16Q and HD-39Q alone, and complexes of Fab and huntingtin exon 1 protein. Fab complexes with HD-16Q were prepared at a 1:1 Fab:HD-16Q molar ratio, while complexes with HD-39Q were prepared at a 3:1 molar ratio. Concentrations of proteins and complexes varied from 1-7 mg/mL, higher than the concentrations used for equilibrium gel 
filtration experiments. As expected, the $\mathrm{R}_{\mathrm{h}}$ values derived for the $3 \mathrm{~B} 5 \mathrm{H} 10$ and MW1 Fabs, which are globular proteins of similar dimensions, were roughly the same, and both $R_{h}$ values were smaller than the $R_{h}$ values for HD-16Q and HD-39Q (Table 2), consistent with the proposed elongated structures of HD-16Q and HD-39Q [3] (Table 2). Notably, the $R_{h}$ value for HD-16Q was smaller than for HD-39Q, inconsistent with the compact structure proposed for expanded polyQ [9]. When complexed with huntingtin exon 1 proteins, both Fabs exhibited qualitatively similar behavior: the $R_{h}$ values were lower for the Fab complexes with $H D-16 Q$ than with HD39Q. Based on our gel filtration and SEC-MALS data (Fig. 2,4), the complexes being examined by DLS were likely to be 1:1 Fab:HD-16Q complexes and a mixture of 2:1 and 3:1 Fab:HD-39Q complexes for both Fabs. Consistent with our other results, the 3B5H10 and MW1 Fabs did not exhibit different properties when binding to huntingtin exon 1 proteins as would have been expected if 3B5H10, but not MW1, recognized a pathologic conformation of expanded polyQ.

\section{Small-angle X-ray scattering revealed similar predicted characteristics for complexes of MW1 and 3B5H10 Fabs with huntingtin exon 1 proteins}

We next repeated published small-angle X-ray scattering (SAXS) studies for HD-39Q alone and complexed with 3B5H10 Fab [9], comparing results with SAXS data for analogous complexes with MW1 Fab and HD-16Q. We collected SAXS data for samples of 3B5H10 and MW1 Fabs alone, HD-16Q, HD-25Q, HD-39Q, and HD-46Q alone, and complexes of each Fab with HD-16Q and HD-39Q. With the exception of the HD-46Q alone sample, the scattering profiles for the Fabs, huntingtin exon 1 fusion proteins alone, and Fab:HD-16Q and Fab:HD39Q complexes showed ideal sample quality characteristics (Fig. S2). Guinier analysis [17] indicated minimal aggregation for both Fabs alone and Fabs complexed with HD-16Q and HD$39 \mathrm{Q}$ and for all huntingtin exon 1 fusion proteins alone (Fig. S3). Radii of gyration $\left(\mathrm{R}_{\mathrm{g}}\right)$ determined by SAXS were consistent with $R_{h}$ values determined by DLS (Table 2). In particular, for measurements of huntingtin exon 1 fusion proteins alone, we did not see substantially 
increased $R_{h}$ or $R_{g}$ values for $H D-39 Q$ compared with $H D-16 Q$, consistent with computational modeling of poly $Q$ in aqueous solution suggesting that radii of poly $Q$ tracts of increasing lengths are similar [18], but inconsistent with the structural toxic threshold model predicting a conformational transition for expanded polyQ tracts [9]. The predicted molecular weights of the complexes of 3B5H10 or MW1 Fab bound to HD-16Q in a 1:1 complex were similar to the molecular weights calculated based on the extrapolated scattering intensity at zero angle [19]. However, 3B5H10 Fab or MW1 Fab bound to HD-39Q formed complexes with observed molecular weights larger than a 1:1 complex. Based on molecular weight alone, these complexes could be 2:1, 3:1, or 2:2 Fab:HD-39Q complexes. A 2:2 3B5H10 Fab:HD-39Q stoichiometry was postulated to account for previous SAXS data [9]. However, our SEC-MALS and equilibrium gel filtration data demonstrated that 3B5H10 Fab does not bind to HD-39Q in a 2:2 ratio (Fig. 2). Therefore, we interpret our SAXS data for both $3 \mathrm{~B} 5 \mathrm{H} 10$ and MW1 Fab binding to HD-39Q as evidence for mixtures of $2: 1$ and 3:1 Fab:HD-39Q complexes.

Kratky analysis was used to evaluate the relative degree of folding of each sample [20]. The Kratky plots for MW1 and 3B5H10 Fabs alone yielded bell-shaped peaks consistent with globular proteins [21, 22] (Fig. 5a). By contrast, the Kratky plots for HD-16Q and HD-39Q were broader, with less degrease at higher scattering angles, consistent with flexible or unfolded proteins [21, 22] (Fig. 5b). Thus we found no evidence for a conformational change occurring for HD-39Q relative to HD-16Q. Similarly, we found no systematic differences for $3 B 5 H 10$ versus MW1 Fab complexes with either HD-16Q or HD-39Q (Fig. 5c,d). These results are consistent with both Fabs exhibiting similar recognition properties for polyQ tracts.

Three-dimensional structures can be modeled into SAXS profiles; however, modeling is limited by the one-dimensional nature of SAXS data, and more than one 3-D shape can produce the same one-dimensional scattering profile [23]. We did not attempt to fit atomistic models into the SAXS data as done in a previous study [9] because (i) the complete 3-D structure of huntingtin exon 1 protein is unknown, (ii) the polyQ tract within huntingtin exon 1 fusion proteins 
adopts flexible random coil structures in solution [3], and (iii) the arrangements between polyQ tracts, the remainder of huntingtin exon 1, the TRX fusion partner, and the His purification tag cannot be predicted. Nor did we assume that the huntingtin exon 1 fusion proteins were dimeric, as also done for interpretation of SAXS data involving HD-39Q bound to 3B5H10 Fab [9], because our SEC-MALS data demonstrated that HD-39Q is monomeric in solution (Fig. 2). Instead, we used minimal assumptions to generate ab initio models that predicted molecular envelopes from the SAXS data for each of the well-behaved samples. We did not find notable differences between 3B5H10:HD-39Q and MW1:HD-39Q complexes based on $R_{g}$, $D_{\max }$, or shape or volume of calculated envelopes (Fig. 6, Table 2), as would be predicted by the toxic conformation model suggesting that $3 \mathrm{~B} 5 \mathrm{H} 10$, but not $\mathrm{MW} 1$, recognizes a compact conformation of expanded polyQ [9]. Instead, in agreement with experiments described above and in previous reports $[3,4,6,12]$, the SAXS results were consistent with recognition of multiple epitopes within a linear lattice of expanded polyQ by both Fabs.

\section{DISCUSSION}

The structure of huntingtin exon 1 protein in the preaggregation state, particularly the conformation of the expanded polyQ repeat, is hypothesized to be critical in understanding the pathogenesis of HD. However, the structure of the basic components of huntingtin exon 1 remains controversial. An X-ray crystal structure of a $Q_{17}$ huntingtin N-terminal region fused to MBP showed that a short polyQ region could adopt either $\alpha$-helical, loop, or random coil conformations [24]. The structure of a $Q_{10}$ peptide bound to the anti-polyQ antibody MW1 revealed an extended structure [4]. Other recent work suggested that the polyQ repeat acts as a flexible hinge that exhibits reduced flexibility at extended polyQ lengths [25]. In the present study, we show that the binding properties of the anti-polyQ antibodies MW1 and 3B5H10 support the 'linear lattice' model for the structure of soluble polyQ in the context of a huntingtin exon 1 fusion protein. This model postulates that both normal and expanded polyQ tracts in the 
preaggregation state are random-coil structures, with expanded polyQ repeats containing more epitopes recognized by antibodies or other binding proteins than normal polyQ tracts [3]. Several lines of evidence, reported here and in previous publications [6, 11], have shown that 3B5H10 and MW1 IgGs can bind to a normal polyQ repeat, demonstrating that neither antibody preferentially recognizes a novel structure formed by expanded polyQ, but instead both recognize a short stretch of polyQ. This conclusion is in contrast to other studies suggesting that $3 \mathrm{~B} 5 \mathrm{H} 10$ bound preferentially to expanded polyQ repeats of mutant huntingtin according to a 'structural toxic threshold' model, in which a conformational transition occurs in the polyQ repeat of huntingtin exon 1 protein at the pathologic threshold (>37Q) [9]. Instead our results agree with the conclusions of a recent study comparing the binding of anti-polyQ antibodies $1 \mathrm{C} 2$ and $3 \mathrm{~B} 5 \mathrm{H} 10$ to polyQ repeats [6].

To evaluate whether an expanded polyQ tract contains one epitope for anti-polyQ Fabs as predicted by the structural toxic threshold model, or multiple epitopes for the Fabs as predicted by the linear lattice model, we evaluated complexes using equilibrium gel filtration chromatography. Our results demonstrated that the stoichiometry of both 3B5H10 Fab:HD-39Q and MW1 Fab:HD-39Q complexes was $~ 3: 1$ Fab:HD-39Q for both Fabs, thus neither Fab preferentially recognizes a novel structure formed by expanded polyQ. Consistent with this result, we confirmed that both 3B5H10 and MW1 IgGs recognized unexpanded polyQ, in direct contradiction to the structural toxic threshold model. We also used SAXS and DLS to further study the conformation of normal and expanded forms of huntingtin exon 1 protein, alone and in complex with MW1 or 3B5H10 Fab. This allowed us to determine the globularity of the protein complexes and their approximate oligomeric states, which revealed striking similarities between MW1 and 3B5H10 Fabs, both when unliganded and when bound to HD-16Q or HD-39Q. Thus a combination of equilibrium gel filtration chromatography, DLS, and SAXS data are consistent with a linear lattice mode of recognition of unstructured polyQ for both 3B5H10 and MW1 antibodies. Sharing the same general ligand-binding properties is consistent with the high 
degree of sequence and structural similarity relating 3B5H10 and MW1 [6]: the variable regions are related by $53 \%\left(\mathrm{~V}_{\mathrm{H}}\right.$ domain $)$ and $99 \%\left(\mathrm{~V}_{\mathrm{L}}\right.$ domain $)$ sequence identity and a root mean square deviation of $0.59 \AA$ for superposition of $V_{H}-V_{L}$ regions of the $3 B 5 H 10$ (PDB code 3S96) and MW1 (PDB code 2GSG) crystal structures (calculated for all $\mathrm{C} \alpha$ atoms). In addition, the antigen-binding sites of both antibodies include an unusual diagonal groove [6] shown to accommodate a single extended stretch of polyQ in an MW1-polyQ co-crystal structure [4], and thus unlikely to bind to a two-stranded $\beta$-hairpin structure of polyQ, as modeled for the HD-39Q interaction with 3B5H10 Fab [9].

Reduced penetrance is seen in patients with between 37 and 41 glutamine repeats in the huntingtin protein, which may be best explained by a quantitative change in a rate-limiting process in which the effects can be countered in some patients and not in others due to environmental or genetic modifiers. This reduced penetrance is consistent with a continuous linear lattice effect that is weak at lower polyQ repeat lengths and progressively stronger at larger repeat lengths. These results are relevant to potential therapeutic approaches to target soluble expanded polyQ in a lag period preceding aggregation. As we find no evidence for recognition of a specific conformation of expanded polyQ within huntingtin exon 1 proteins in either this study or previous studies $[3,4,6,12]$, we suggest that efforts to target expanded polyQ using monomeric binding partners are unlikely to be successful in discriminating poly $Q$ stretches found in non-disease proteins such as transcription factors [26, 27] from expanded polyQ within mutant huntingtin exon 1. Instead, we suggest strategies in which reagents that recognize short stretches of polyQ are covalently linked to allow avidity effects to discriminate between short and expanded polyQ tracts.

\section{MATERIALS AND METHODS}

\section{Protein expression and purification}

Human huntingtin exon 1 encoded protein (comprising 91 amino acids when containing 
16 glutamine residues) including different sized polyQ segments (Q16, Q25, Q39, and Q46) coded for by CAG or CAA/CAG repeats was expressed as a fusion protein with thioredoxin (TRX). Exon 1 fusion proteins were purified as previously described [3] with the following modifications: autoinduction was used to culture cells to high densities [28], and sonication was used for cell lysis. Purified proteins were flash frozen and stored at $-80^{\circ} \mathrm{C}$ in $50 \mathrm{mM}$ Tris (pH 8.0) and $150 \mathrm{mM} \mathrm{NaCl}$.

MW1 IgG2b was purified from ascites fluid by protein A affinity chromatography (GE Healthcare). MW1 Fab was prepared by papain cleavage of MW1 IgG using a ratio of 1:25 (papain:MW1 by weight) for 30 minutes at $37^{\circ} \mathrm{C}$. Fabs were separated from the Fc fragment using protein A affinity chromatography (GE Healthcare) and then further purified by gel filtration chromatography (Superdex 200 10/300 GL).

3B5H10 Fab was expressed and purified as previously described for other IgGs [29]. Briefly, the 3B5H10 light chain (LC) gene and a C-terminally $6 \mathrm{x}-\mathrm{His}$ tagged heavy chain (HC) gene were subcloned separately into the pTT5 mammalian expression vector (NRC Biotechnology Research Institute), and 3B5H10 Fab was expressed by transient co-transfection of HEK293-6E (NRC Biotechnology Research Institute) cells and purified from supernatants using $\mathrm{Ni}^{2+}$-NTA affinity chromatography and gel filtration chromatography (Superdex 200 10/300 or 16/60).

Protein concentrations were determined using $280 \mathrm{~nm}$ extinction coefficients of 80,830 $\mathrm{M}^{-1} \mathrm{~cm}^{-1}$ (3B5H10 Fab), 78,310 $\mathrm{M}^{-1} \mathrm{~cm}^{-1}$ (MW1 Fab), 14,180 $\mathrm{M}^{-1} \mathrm{~cm}^{-1}$ (TRX), 14,180 $\mathrm{M}^{-1} \mathrm{~cm}^{-1}$ (HD-16Q), and 14,180 $\mathrm{M}^{-1} \mathrm{~cm}^{-1}$ (HD-39Q). Extinction coefficients were calculated based on amino acid sequence using ProtParam (http://web.expasy.org/protparam/protpar-ref.html).

\section{Western and dot blot analyses}

Equimolar amounts of purified huntingtin exon 1 protein and TRX were loaded and separated on an Any kD Mini-PROTEAN gel (Bio-Rad Laboratories, Hercules, CA) at $175 \mathrm{~V}$ for 
40 minutes, followed by transfer to a nitrocellulose membrane at $100 \mathrm{~V}$ for 1 hour. After blocking for 1 hour in TBST with 3\% BSA, membranes were incubated overnight at $4^{\circ} \mathrm{C}$ with $3 \mathrm{~B} 5 \mathrm{H} 10 \lg$ (Sigma, St. Louis, MO), MW1 IgG (purified from ascites), or rabbit polyclonal N17 huntingtin IgG [30] at 1:75,000 or, 1:10,000, or 1:7,500 respectively. Membranes were washed with TBST and incubated with HRP-conjugated anti-mouse IgG (Jackson Immunoresearch Laboratories, West Grove, PA) or HRP-conjugated anti-rabbit IgG (Jackson Immunoresearch Laboratories) for 1 hour at room temperature. Membranes were washed again, and antibody binding was detected using Amersham Enhanced Chemiluminescence (ECL) Prime Western Blotting Detection Reagent (GE Life Sciences, Uppsala, Sweden). Western blots were imaged using a ChemiDoc MP Imaging System (Bio-Rad Laboratories). Equimolar amounts of purified huntingtin exon 1 protein and TRX were also analyzed by SDS-PAGE on an Any kD Mini-PROTEAN gel (Bio-Rad Laboratories) and stained with Coomassie.

Equimolar amounts of huntingtin exon 1 fusion protein and TRX were serially diluted in $50 \mathrm{mM}$ Tris (pH 8.0), $150 \mathrm{mM} \mathrm{NaCl}$ and spotted onto nitrocellulose membranes. Membranes were washed with TBST and probed with 3B5H10, MW1, or mouse monoclonal anti-TRX (Genscript, Piscataway, NJ) IgGs overnight at $4^{\circ} \mathrm{C}$. HRP-conjugated goat anti-mouse secondary antibody (Jackson Immunoresearch Laboratories) was used to quantitate antibody binding to proteins on the membrane, and antibody binding was detected using Amersham ECL Prime Western Blotting Detection Reagent (GE Life Sciences). Densitometry of blots was performed using Image Lab 5.2.1 Software (Bio-Rad Laboratories). Densities were expressed as a ratio relative to the density observed for HD-16Q (western blots) or 20 pmol HD-16Q (dot blots).

\section{SEC-MALS}

Purified proteins or protein complexes were characterized by SEC-MALS to determine absolute molecular masses [13]. Proteins were concentrated to $1 \mathrm{mg} / \mathrm{mL}$, passed through a 0.2 $\mu \mathrm{m}$ filter (Millipore), and injected onto a Superdex 200 10/300 GL gel-filtration chromatography 
column equilibrated in a buffer containing $20 \mathrm{mM}$ Tris $(\mathrm{pH} 8.0)$ and $100 \mathrm{mM} \mathrm{NaCl}$. The chromatography system was connected with an 18-angle light-scattering detector (DAWN HELEOS II; Wyatt Technology), a dynamic light-scattering detector (DynaPro Nanostar; Wyatt Technology), and a refractive index detector (Optilab t-rEX; Wyatt Technology). Data were collected every second at a flow rate of $0.5 \mathrm{~mL} / \mathrm{min}$ at $25^{\circ} \mathrm{C}$. Data analysis was carried out using the program ASTRA 6, yielding the molar mass and distribution of mass (polydispersity) of the sample.

\section{Non-equilibrium gel filtration chromatography}

Non-equilibrium protein interaction experiments were carried out on a Superdex 200 PC 3.2/30 gel-filtration column (GE Healthcare) equilibrated in a buffer containing $50 \mathrm{mM}$ Tris (pH 8.0) and $150 \mathrm{mM} \mathrm{NaCl}$. A final concentration of $7 \mu \mathrm{M} \mathrm{HD}-39 \mathrm{Q}$ was used for all experiments, with 3B5H10 and MW1 Fab concentrations varied to create Fab:HD-39Q complexes with final molar ratios of $0.25: 1,0.5: 1,1: 1,1.5: 1,2: 1$, and $3: 1.50 \mu \mathrm{L}$ of each complex was injected and flowed through the column at $50 \mu \mathrm{L} / \mathrm{min}$ at room temperature. The absorbance of the eluent was monitored at $280 \mathrm{~nm}$.

\section{Equilibrium gel filtration chromatography}

A Superdex 200 PC 3.2/30 (GE Healthcare) gel filtration column was equilibrated and run with equilibration buffer: $50 \mathrm{mM}$ Tris $(\mathrm{pH} 8.0), 150 \mathrm{mM} \mathrm{NaCl}$ and a specific concentration of 3B5H10 Fab $(0.5 \mu \mathrm{M}, 0.75 \mu \mathrm{M}, 1 \mu \mathrm{M}$, or $5 \mu \mathrm{M})$ or MW1 Fab $(1 \mu \mathrm{M}, 3 \mu \mathrm{M}, 5 \mu \mathrm{M}$, or $10 \mu \mathrm{M})$. Complexes containing $0: 1,1: 1,2: 1$, or $3: 1$ molar ratios of a variable concentration of Fab:HD$39 \mathrm{Q}$, where the concentration of HD-39Q was equal to the concentration of Fab in the equilibration buffer, were incubated for 30 minutes at room temperature in equilibration buffer and then injected onto the column. Chromatography was performed at a flow rate of $50 \mu \mathrm{L} / \mathrm{min}$ using a SMART micropurification system (Pharmacia), and the absorbance of the eluent was 
monitored at $280 \mathrm{~nm}$.

\section{Dynamic light scattering (DLS)}

DLS measurements were conducted on a DynaPro® NanoStar ${ }^{\mathrm{TM}}$ (Wyatt Technology, Goleta, CA) at $25^{\circ} \mathrm{C}$. All samples were purified using a Superdex $20010 / 300$ column in $50 \mathrm{mM}$ Tris (pH 8.0), $150 \mathrm{mM} \mathrm{NaCl}$ prior to DLS and SAXS measurements, and the same sample preparations were used for both experiments. Fractions were pooled and concentrated to at least $2 \mathrm{mg} / \mathrm{mL}$ and filtered through $0.2 \mu \mathrm{m}$ membranes (Millipore). Samples were equilibrated to $25^{\circ} \mathrm{C}$ prior to DLS measurements. Data were analyzed using Dynamics V7.1.2 software (Wyatt Technology) to calculate hydrodynamic radii $\left(R_{h}\right)$.

\section{Small angle X-ray scattering (SAXS)}

Small angle X-ray scattering experiments were conducted at beamline 4-2 at SSRL using a Rayonix MX225-HE detector at a distance of $2500 \mathrm{~mm}$, using $1.13 \AA$ wavelength Xrays. Protein preparations for DLS measurements were used for SAXS data collection. For each protein or complex, scattering intensity was measured at four protein concentrations $(0.5-7$ $\mathrm{mg} / \mathrm{mL}$ ), collecting 10 exposures of 1 second each, covering a momentum transfer (q) range of 0.0047-0.375 1/Å. The scattering profile for the buffer was obtained in the same manner. Scattering curves collected from protein samples were corrected for background scattering using the intensity data collected from the buffer alone using SasTool [31].

SAXS scattering curves were scaled, high and low q regions of scattering curves were merged to extrapolate to infinite dilution, and Guinier analysis was performed using PRIMUS [32]. $R_{g}$ values were calculated from Guinier plots. Scattering curves were overlaid to check for concentration-dependent effects on the scattering profile. GNOM [17] was used to calculate pairwise distribution functions. Porod volumes were calculated from DATPOROD [33]. Molecular weight was calculated by using the formula $\mathrm{MM}_{\mathrm{p}}=I(0)_{\mathrm{p}} / \mathrm{c}_{\mathrm{p}}{ }^{*}\left(\mathrm{MM}_{\mathrm{st}}\right) /\left(I(0)_{\mathrm{st}} / \mathrm{c}_{\mathrm{st}}\right)$, where 
$\mathrm{MM}_{\mathrm{p}}$ and $\mathrm{MM}_{\mathrm{st}}$ are molecular masses of the protein and lysozyme standard, respectively, $I(0)_{\mathrm{p}}$ and $I(0)_{\mathrm{st}}$ are the scattering angles at zero intensity, and $\mathrm{c}_{\mathrm{p}}$ and $\mathrm{c}_{\mathrm{st}}$ are the concentrations [19]. The protein concentration, $c_{p}$, was calculated using the equation $A=\varepsilon L c_{p}$, where $A$ is absorbance at $280 \mathrm{~nm}, \varepsilon$ is the molar extinction coefficient, and $L$ is the path length. The extinction coefficient and theoretical molecular weight for a 3:1 and a 1:1 Fab:huntingtin exon 1 protein complex are different. Because we most likely observed a mixture of $1: 1,2: 1$, and 3:1 Fab:huntingtin complexes, we listed a lower limit (100\% 1:1) and upper limit (100\% 3:1) for potential complex sizes.

For each protein or complex, at least 10 ab initio models were generated using DAMMIF [34]. Models were superimposed and averaged using DAMMIN [35] and DAMAVER [36] in the ATSAS package [33], and resulting models were filled with dummy atoms.

\section{Author contributions}

G.E.O. and P.J.B. conceived the study; G.E.O. and D.M.N. performed protein expression, purification, western and dot blots, and SEC-MALS; G.E.O. performed equilibrium gel filtration assays; G.E.O., A.P.W., and P.J.B. analyzed the data; and G.E.O. and P.J.B. wrote the paper with all co-authors contributing to scientific planning and discussions.

\section{ACKNOWLEDGEMENTS}

We thank Beth Huey-Tubman and Alejandra Olvera for technical support; Thomas Weiss, Lester Carter, and the scientific staff of SSRL beamline 4-2 for help with SAXS experiments; Tobias Stuwe for assistance with SEC-MALS experiments; and Beth Stadtmueller and Melanie Brewer for critical reading of the manuscript. We thank R.S. Atwal at the Massachusetts General Hospital for providing the N17 antibody. We acknowledge the Gordon and Betty Moore Foundation for support of the Molecular Observatory at Caltech. The operations at SSRL are supported by the Department of Energy and by the National Institutes of 
Health. G.E.O. was supported by a National Research Service Award (T32GM7616) from the National Institute of General Medical Sciences and by the Center for Advancement of Science in Space (CASIS).

\section{FIGURE LEGENDS}

Fig. 1. Biochemical analyses of huntingtin exon 1:3B5H10 IgG and huntingtin exon 1:MW1 IgG complexes. (a) Schematic of organization of human huntingtin exon 1- thioredoxin (TRX) fusion proteins used in this study. The bar above the domain structure represents the huntingtin exon 1 fragment with the polyQ tract indicated by a bracket. N17, N-terminal 17 amino acid domain. PRR, proline rich region. (b) Western blot analysis of 3B5H10 and MW1 IgG binding to huntingtin exon 1 fusion proteins with variable numbers of glutamines. Both MW1 and 3B5H10 IgGs bound to huntingtin exon 1 proteins with normal and expanded polyQ repeats, but did not bind the TRX-tag control (top panels). Equimolar loading of huntingtin exon 1 fusion proteins was verified by blotting with the N17 antibody that recognizes the first 17 residues of huntingtin [30] (bottom panel). Densitometry of bands in blots is shown in Fig. S1b. (c) Dot blot analysis of $3 \mathrm{~B} 5 \mathrm{H} 10$ and $\mathrm{MW} 1 \mathrm{lgG}$ binding to huntingtin exon 1 fusion proteins (top panels). Equimolar loading of huntingtin proteins was verified by blotting with anti-TRX (bottom panel).

Densitometry results are shown in Fig. S1c. As huntingtin concentrations decreased, binding to short polyQ repeats of huntingtin exon 1 protein was reduced more than binding to long polyQ repeats for both anti-polyQ antibodies MW1 and 3B5H10.

Fig. 2. SEC-MALS profiles of huntingtin exon 1 protein and Fab:huntingtin exon 1 complexes. Complexes were prepared with $\sim 3$-fold molar excess of Fab for experiments with HD-39Q and equal molar ratios for experiments with HD-16Q and then injected onto a Superdex 200 10/300 GL gel filtration column. The differential refractive index (left axis) is plotted against elution time from a gel filtration column and overlaid with the molar mass determined for each peak (right 
axis).

Fig. 3. Non-equilibrium gel filtration chromatography analyses of Fab:HD-39Q complexes. Fabs of MW1 or 3B5H10 and HD-39Q were incubated at Fab:HD-39Q molar ratios of 0.25:1, 0.5:1, $1: 1,1.5: 1,2: 1$, and $3: 1$, and passed over a gel filtration column run under non-equilibrium conditions. An HD-39Q concentration of $7 \mu \mathrm{M}$ was used for all experiments. (a) $3 \mathrm{~B} 5 \mathrm{H} 10 \mathrm{Fab}$ in complex with HD-39Q. (b) MW1 Fab in complex with HD-39Q.

Fig. 4. Equilibrium gel filtration chromatography analyses of Fab:HD-39Q complexes. MW1 or 3B5H10 Fabs and HD-39Q were incubated at the indicated molar ratios and passed over a gel filtration column run in an equilibration buffer containing the indicated concentrations of $3 \mathrm{~B} 5 \mathrm{H} 10$ or MW1 Fab. For each experiment, HD-39Q at the same concentration as the Fab in the equilibration buffer was incubated with Fab at Fab:HD-39Q molar ratios of $0: 1,1: 1,2: 1$, and 3:1 in the equilibration buffer and injected onto a column that had been equilibrated in the equilibration buffer. The peak eluting first corresponds to a Fab:HD-39Q complex. The second peak or trough occurs at the volume where free Fab elutes. (a) 3B5H10 Fab in complex with HD-39Q using $0.5 \mu \mathrm{M}, 0.75 \mu \mathrm{M}, 1.0 \mu \mathrm{M}$, and $5 \mu \mathrm{M}$ 3B5H10 Fab in the equilibration buffer. (b) MW1 Fab in complex with HD-39Q using $1 \mu \mathrm{M}, 3 \mu \mathrm{M}, 5 \mu \mathrm{M}$, and $10 \mu \mathrm{M}$ MW1 Fab in the equilibration buffer. The stoichiometry approached 3:1 Fab:HD-39Q for both Fabs.

Fig. 5. Kratky plot analyses of SAXS data for huntingtin exon 1 fusion proteins, MW1 and 3B5H10 Fabs, and complexes of Fabs and huntingtin exon 1 proteins. Each plot shows the intensity of scattering plotted as $\mathrm{Iq}^{2}$ versus $\mathrm{q}$, where $\mathrm{q}$ is scattering angle $\left(\AA^{-1}\right)$ and $\mathrm{I}$ is the scattering intensity. (a) For MW1 and 3B5H10 Fabs, each plot exhibited one maximum, indicating that these are globular proteins. (b) HD-16Q and HD-39Q showed a plateau at higher q values, suggesting that these proteins include disordered regions, with decreasing globular 
character as the polyQ repeat length increased. (c) Curves for 3B5H10:HD-16Q and MW1:HD16Q complexes were similar, each exhibiting broad single peaks. (d) Curves for 3B5H10:HD39Q and MW1:HD-39Q complexes were similar, each exhibiting a similar low plateau.

Fig. 6. Ab initio models derived from SAXS data for huntingtin exon 1 fusion proteins, MW1 and 3B5H10 Fabs, and Fabs:huntingtin exon 1 complexes. Calculated molecular envelopes filled with dummy atoms reveal the shapes of (a) 3B5H10 Fab, MW1 Fab, HD-16Q, HD-39Q, (b) 3B5H10 Fab:HD-16Q, MW1 Fab:HD-16Q, 3B5H10 Fab:HD-39Q, MW1 Fab:HD-39Q. 


\section{REFERENCES}

[1] Zuccato C, Valenza M, Cattaneo E. Molecular mechanisms and potential therapeutical targets in Huntington's disease. Physiological reviews. 2010;90:905-81.

[2] Hendricks AE, Latourelle JC, Lunetta KL, Cupples LA, Wheeler V, MacDonald ME, et al. Estimating the probability of de novo HD cases from transmissions of expanded penetrant CAG alleles in the Huntington disease gene from male carriers of high normal alleles (27-35 CAG). American journal of medical genetics Part A. 2009;149A:1375-81.

[3] Bennett MJ, Huey-Tubman KE, Herr AB, West AP, Jr., Ross SA, Bjorkman PJ. A linear lattice model for polyglutamine in CAG-expansion diseases. Proceedings of the National Academy of Sciences of the United States of America. 2002;99:11634-9.

[4] Li P, Huey-Tubman KE, Gao T, Li X, West AP, Jr., Bennett MJ, et al. The structure of a polyQ-anti-polyQ complex reveals binding according to a linear lattice model. Nature structural \& molecular biology. 2007;14:381-7.

[5] Trottier Y, Lutz Y, Stevanin G, Imbert G, Devys D, Cancel G, et al. Polyglutamine expansion as a pathological epitope in Huntington's disease and four dominant cerebellar ataxias. Nature. 1995;378:4.

[6] Klein FA, Zeder-Lutz G, Cousido-Siah A, Mitschler A, Katz A, Eberling P, et al. Linear and extended: a common polyglutamine conformation recognized by the three antibodies MW1, 1C2 and 3B5H10. Human molecular genetics. 2013;22:4215-23.

[7] Nagai Y, Inui T, Popiel HA, Fujikake N, Hasegawa K, Urade Y, et al. A toxic monomeric conformer of the polyglutamine protein. Nature structural \& molecular biology. 2007;14:332-40. [8] Miller J, Arrasate M, Brooks E, Libeu CP, Legleiter J, Hatters D, et al. Identifying polyglutamine protein species in situ that best predict neurodegeneration. Nature chemical biology. 2011;7:925-34.

[9] Peters-Libeu C, Miller J, Rutenber E, Newhouse Y, Krishnan P, Cheung K, et al. Diseaseassociated polyglutamine stretches in monomeric huntingtin adopt a compact structure. Journal of molecular biology. 2012;421:587-600.

[10] Fodale V, Kegulian NC, Verani M, Cariulo C, Azzollini L, Petricca L, et al. Polyglutamineand temperature-dependent conformational rigidity in mutant huntingtin revealed by immunoassays and circular dichroism spectroscopy. PloS one. 2014;9:e112262.

[11] Cui X, Liang Q, Liang Y, Lu M, Ding Y, Lu B. TR-FRET assays of Huntingtin protein fragments reveal temperature and PolyQ length-dependent conformational changes. Scientific reports. 2014;4:5601.

[12] Klein FA, Pastore A, Masino L, Zeder-Lutz G, Nierengarten H, Oulad-Abdelghani M, et al. Pathogenic and non-pathogenic polyglutamine tracts have similar structural properties: towards a length-dependent toxicity gradient. Journal of molecular biology. 2007;371:235-44.

[13] Wyatt PJ. Light scattering and the absolute characterization of macromolecules. Analytica Chimica Acta. 1993;272:40.

[14] Sanchez LM, Penny DM, Bjorkman PJ. Stoichiometry of the interaction between the major histocompatibility complex-related Fc receptor and its Fc ligand. Biochemistry. 1999;38:9471-6.

[15] West AP, Jr., Giannetti AM, Herr AB, Bennett MJ, Nangiana JS, Pierce JR, et al. Mutational analysis of the transferrin receptor reveals overlapping HFE and transferrin binding sites.

Journal of molecular biology. 2001;313:385-97.

[16] Hummel JP, Dreyer WJ. Measurement of protein-binding phenomena by gel filtration. Biochim Biophys Acta. 1962;63:530-2.

[17] Svergun DI. Determination of the regularization parameter in indirect-transform methods using perceptual critera. Journal of applied crystallography. 1992;25:495-503.

[18] Vitalis A, Wang X, Pappu RV. Atomistic simulations of the effects of polyglutamine chain length and solvent quality on conformational equilibria and spontaneous homodimerization. Journal of molecular biology. 2008;384:279-97. 
[19] Mylonas E, Svergun DI. Accuracy of molecular mass determination of proteins in solution by small-angle X-ray scattering. Journal of applied crystallography. 2007;40:s245-s9.

[20] Mertens HD, Svergun DI. Structural characterization of proteins and complexes using small-angle X-ray solution scattering. Journal of structural biology. 2010;172:128-41.

[21] Rambo RP, Tainer JA. Accurate assessment of mass, models and resolution by smallangle scattering. Nature. 2013;496:477-81.

[22] Putnam CD, Hammel M, Hura GL, Tainer JA. X-ray solution scattering (SAXS) combined with crystallography and computation: defining accurate macromolecular structures, conformations and assemblies in solution. Quarterly reviews of biophysics. 2007;40:191-285. [23] Trewhella J, Hendrickson WA, Kleywegt GJ, Sali A, Sato M, Schwede T, et al. Report of the wwPDB Small-Angle Scattering Task Force: data requirements for biomolecular modeling and the PDB. Structure. 2013;21:875-81.

[24] Kim MW, Chelliah Y, Kim SW, Otwinowski Z, Bezprozvanny I. Secondary structure of Huntingtin amino-terminal region. Structure. 2009;17:1205-12.

[25] Caron NS, Desmond CR, Xia J, Truant R. Polyglutamine domain flexibility mediates the proximity between flanking sequences in huntingtin. Proceedings of the National Academy of Sciences of the United States of America. 2013;110:14610-5.

[26] Butland SL, Devon RS, Huang Y, Mead CL, Meynert AM, Neal SJ, et al. CAG-encoded polyglutamine length polymorphism in the human genome. BMC genomics. 2007;8:126.

[27] Schaefer MH, Wanker E, Andrade-Navarro MA. Evolution and function of CAG/polyglutamine repeats in protein-protein interaction networks. Nucleic acids research. 2012;40:4273-87.

[28] Studier FW. Protein production by auto-induction in high density shaking cultures. Protein expression and purification. 2005;41:207-34.

[29] Diskin R, Scheid JF, Marcovecchio PM, West AP, Jr., Klein F, Gao H, et al. Increasing the potency and breadth of an HIV antibody by using structure-based rational design. Science. 2011;334:1289-93.

[30] Atwal RS, Desmond CR, Caron N, Maiuri T, Xia J, Sipione S, et al. Kinase inhibitors modulate huntingtin cell localization and toxicity. Nature chemical biology. 2011;7:453-60. [31] Smolsky I, Liu P, Niebuhr M, Ito K, Weiss TM, Tsuruta H. Biological small-angle X-ray scattering facility at the Stanford Synchrotron Radiation Laboratory. Journal of applied crystallography. 2007;40:453-8.

[32] Konarev PV, Volkov VV, Sokolava AV, Koch MHJ, Svergun DI. PRIMUS- a Windows-PC based system for small-angle scattering data analysis. Journal of applied crystallography. 2003;36:1277-82.

[33] Petoukhov MV, Franke DS, Shkumatov AV, Tria G, Kikhney AG, Gajda M, et al. New developments in the ATSAS program package for small-angle scattering data analysis. Journal of applied crystallography. 2012;45:342-50.

[34] Franke DS, Svergun DI. DAMMIF, a program for rapid ab-initio shape determination in small-angle scattering. Journal of applied crystallography. 2009;42:342-6.

[35] Svergun DI. Restoring low resolution structure of biological macromolecules from solution scattering using simulated annealing. Biophysical journal. 1999:2897-86.

[36] Volkov VV, Svergun DI. Uniqueness of ab-initio shape determination in small-angle scattering. Journal of applied crystallography. 2003;36:860-4.

[37] Petoukhov MV, Konarev PV, Kikhney AG, Svergun DI. ATSAS 2.1 - towards automated and web-supported small-angle scattering data analysis. Journal of applied crystallography. 2007;40:6. 


\begin{tabular}{|l|l|l|}
\hline Molecule or complex & \multicolumn{2}{|l|}{ SEC-MALS Molecular Mass (kDa) } \\
\hline & Observed & Calculated \\
\hline HD-16Q & 23.1 & 24.3 \\
\hline HD-39Q & 24.3 & 27.2 \\
\hline 3B5H10 Fab & 44.7 & 48.1 \\
\hline HD-16Q + 3B5H10 Fab & 63.0 & $72.4(1: 1)$ \\
\hline HD-39Q + 3B5H10 Fab & 110.3 & $75.3(1: 1)$ \\
& & $123.5(2: 1)$ \\
& & $171.5(3: 1)$ \\
\hline
\end{tabular}

Table 1. SEC-MALS analysis of huntingtin exon 1 proteins and 3B5H10 Fab:huntingtin exon 1 complexes. The observed and calculated molecular masses of the proteins are listed.

\begin{tabular}{|c|c|c|c|c|c|c|}
\hline $\begin{array}{l}\text { Molecule or } \\
\text { complex }\end{array}$ & $\begin{array}{l}\text { MW (kDa), } \\
\text { calculated }\end{array}$ & $\begin{array}{l}\text { MW (kDa), } \\
\text { observed }\end{array}$ & $\begin{array}{l}\mathbf{R}_{h} \\
(\dot{A})\end{array}$ & $\begin{array}{l}\mathbf{R}_{\mathbf{g}} \\
(\AA)\end{array}$ & $\begin{array}{l}\mathbf{D}_{\max } \\
(\hat{A})\end{array}$ & $\begin{array}{l}\text { Porod volume } \\
\left(10^{5}\right)\left(\AA^{3}\right)\end{array}$ \\
\hline 3B5H10 Fab & 48,118 & 54,900 & 33 & 28 & 98 & 0.6 \\
\hline MW1 Fab & 47,330 & 49,300 & 33 & 26 & 87 & 0.6 \\
\hline HD-16Q & 24,279 & 40,000 & 40 & 49 & 168 & 0.8 \\
\hline HD-39Q & 27,226 & 21,700 & 47 & 52 & 164 & 0.9 \\
\hline $\begin{array}{l}\text { 3B5H10 } \\
\text { Fab:HD-16Q }\end{array}$ & 72,379 & 62,600 & 37 & 35 & 128 & 0.8 \\
\hline $\begin{array}{l}\text { MW1 Fab:HD- } \\
\text { 16Q }\end{array}$ & 71,609 & 71,200 & 41 & 40 & 141 & 0.9 \\
\hline $\begin{array}{l}\text { 3B5H10 } \\
\text { Fab:HD-39Q }\end{array}$ & $\begin{array}{c}75,344(1: 1) \\
171,579(3: 1)\end{array}$ & $\begin{array}{c}137,000- \\
178,000\end{array}$ & 59 & 54 & 194 & 3 \\
\hline $\begin{array}{l}\text { MW1 Fab:HD- } \\
39 Q\end{array}$ & $\begin{array}{c}74,556(1: 1) \\
169,216(3: 1)\end{array}$ & $\begin{array}{c}125,000- \\
162,000\end{array}$ & 52 & 50 & 173 & 2 \\
\hline
\end{tabular}

Table 2. Structural parameters of huntingtin exon 1 proteins, MW1 and 3B5H10 Fabs, and Fab:huntingtin exon 1 protein complexes from SAXS and DLS. MW observed, $R_{g}, D_{\max }$, and Porod volume were obtained from SAXS. $R_{h}$ was obtained from DLS. The extinction coefficient and theoretical molecular weight for a 3:1 and a 1:1 Fab:huntingtin exon 1 protein complex are different; therefore two molecular weights are listed as observed for Fab:HD-39Q complexes. 
DLS and SAXS experiments were performed on the same samples. MW, molecular weight. $R_{h}$, hydrodynamic radius. $R_{g}$, radius of gyration. $D_{\max }$, the maximum linear dimension of scattered particles. 
(a)

Huntingtin exon 1

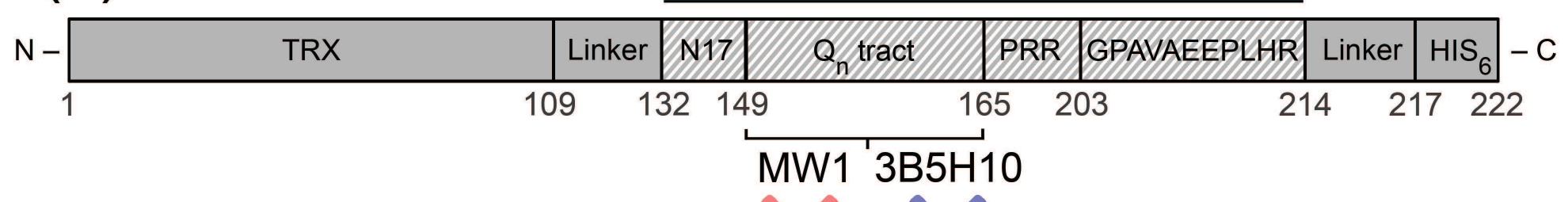

(b)

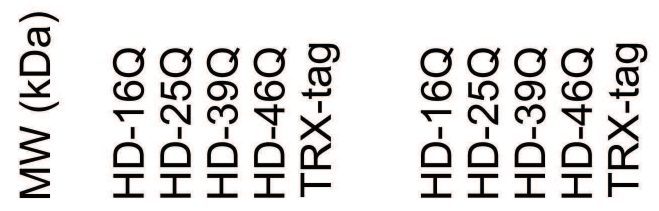

$75-$

$50-$

$37-$

$25-$

$20-$

MW1 IgG $\quad 3 B 5 H 10 \lg G$

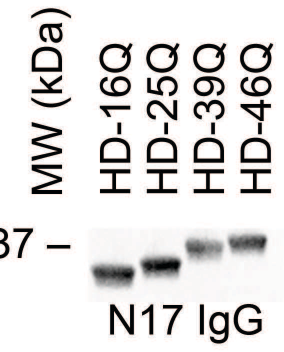

(c)

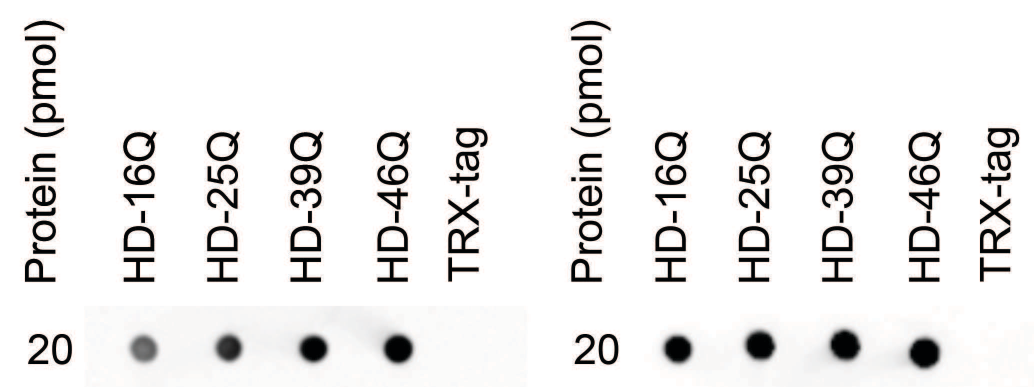

$6.7 \ominus \bullet \bullet \bullet .7$

$2.2 \div \quad \circ \quad \circ$

$\begin{array}{ll}0.7 & 0.7\end{array}$

$\begin{array}{ll}0.2 & 0.2\end{array}$

MW1 lgG

3B5H10 lgG

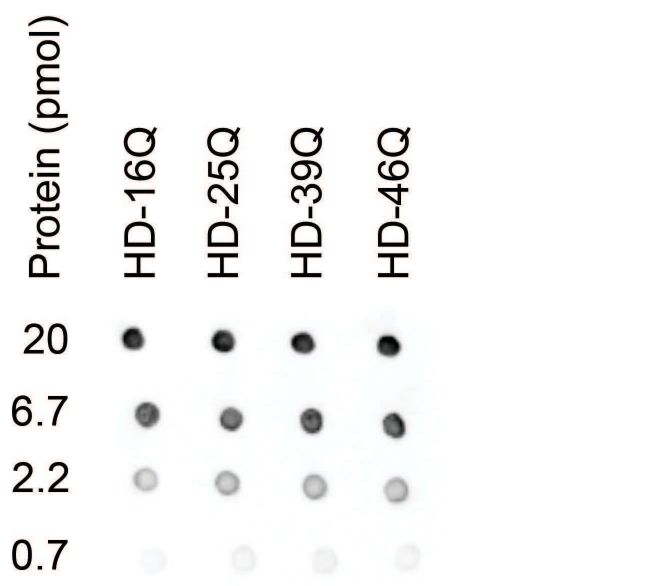

Anti-TRX IgG 


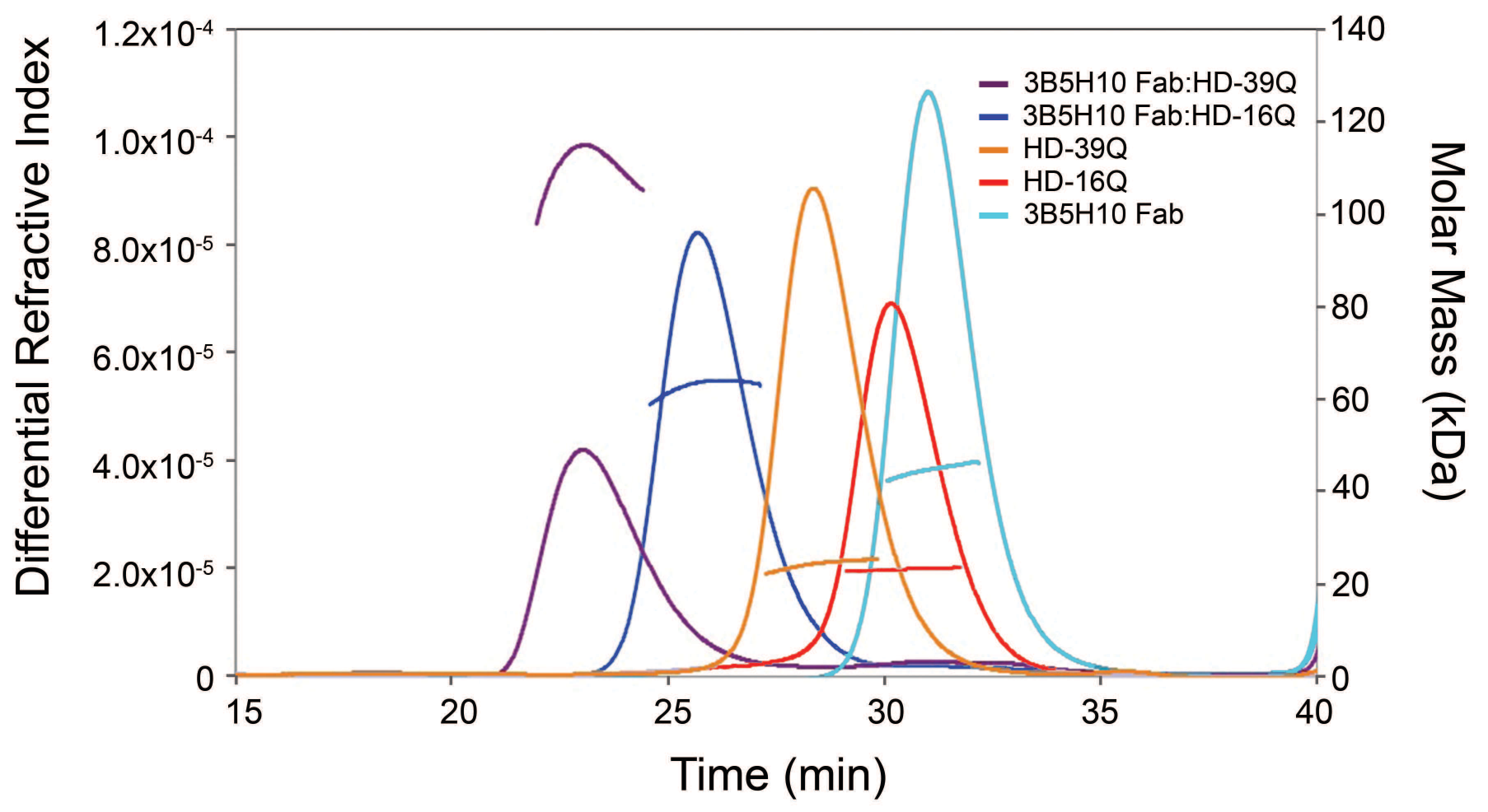

Figure 2 
(a)
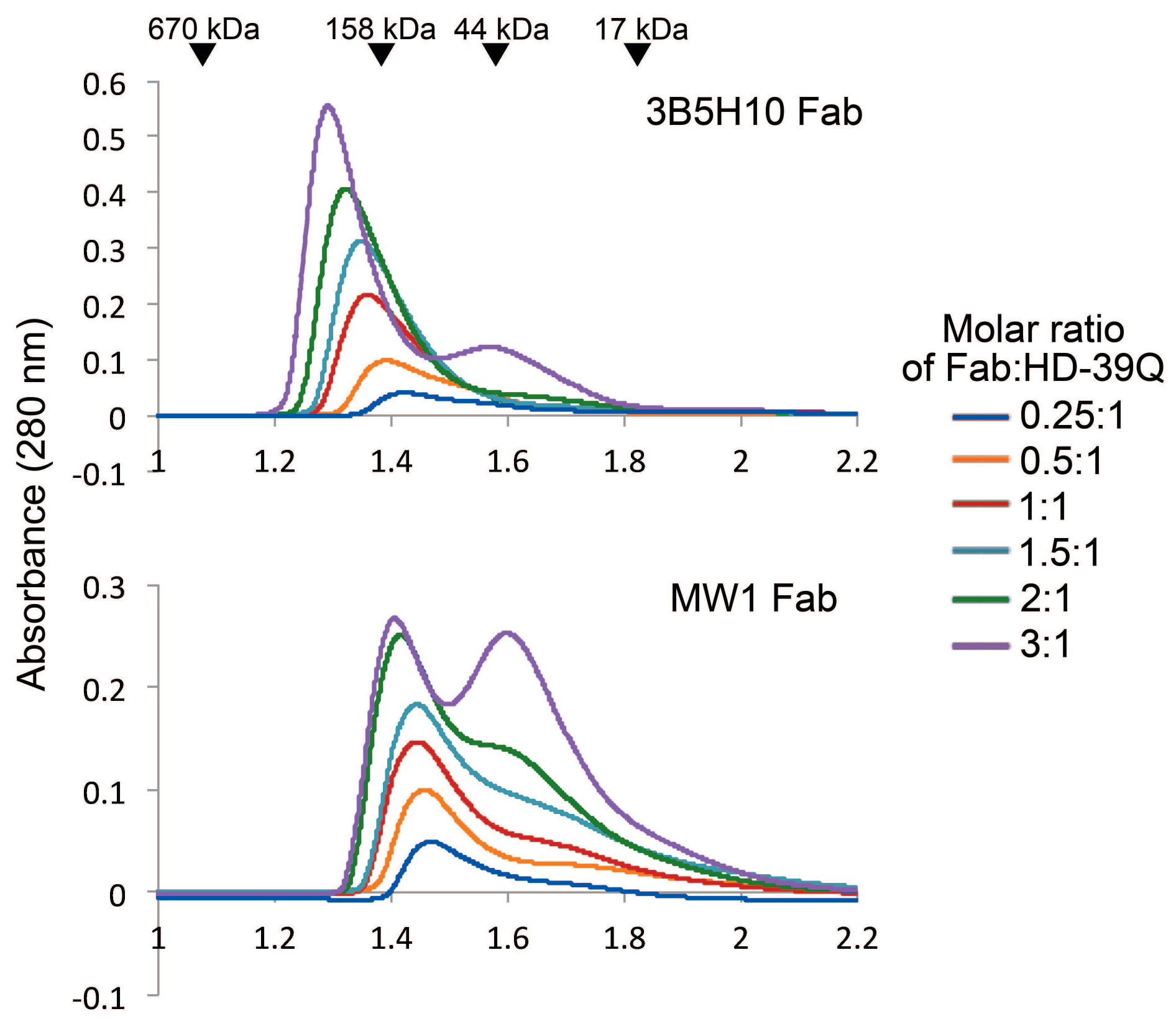

Elution volume (mL)

Figure 3 
(a)

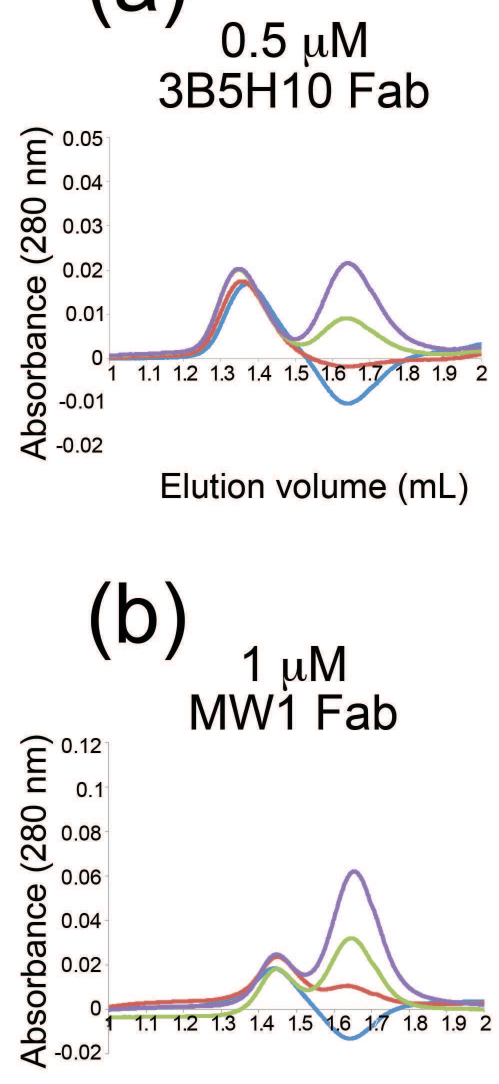

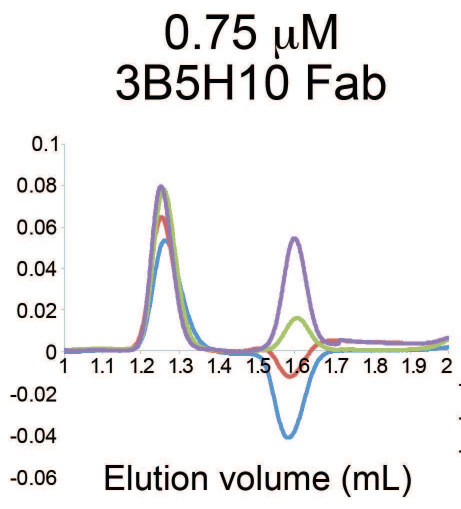

3B5H10 Fab

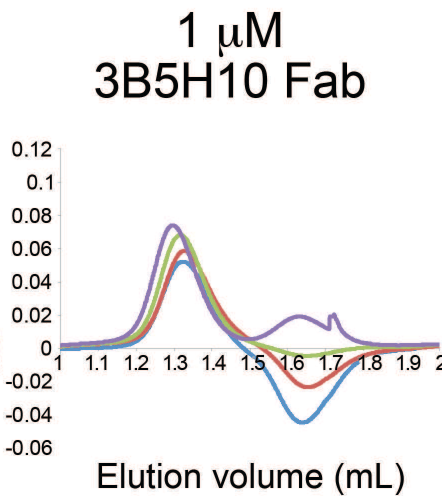

Elution volume $(\mathrm{mL})$

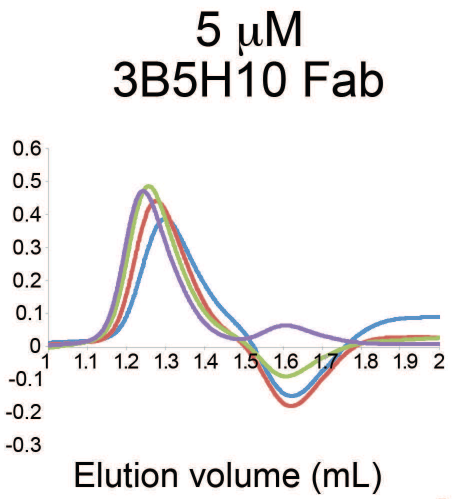

Elution volume $(\mathrm{mL})$

Molar ratio of Fab:HD-39Q

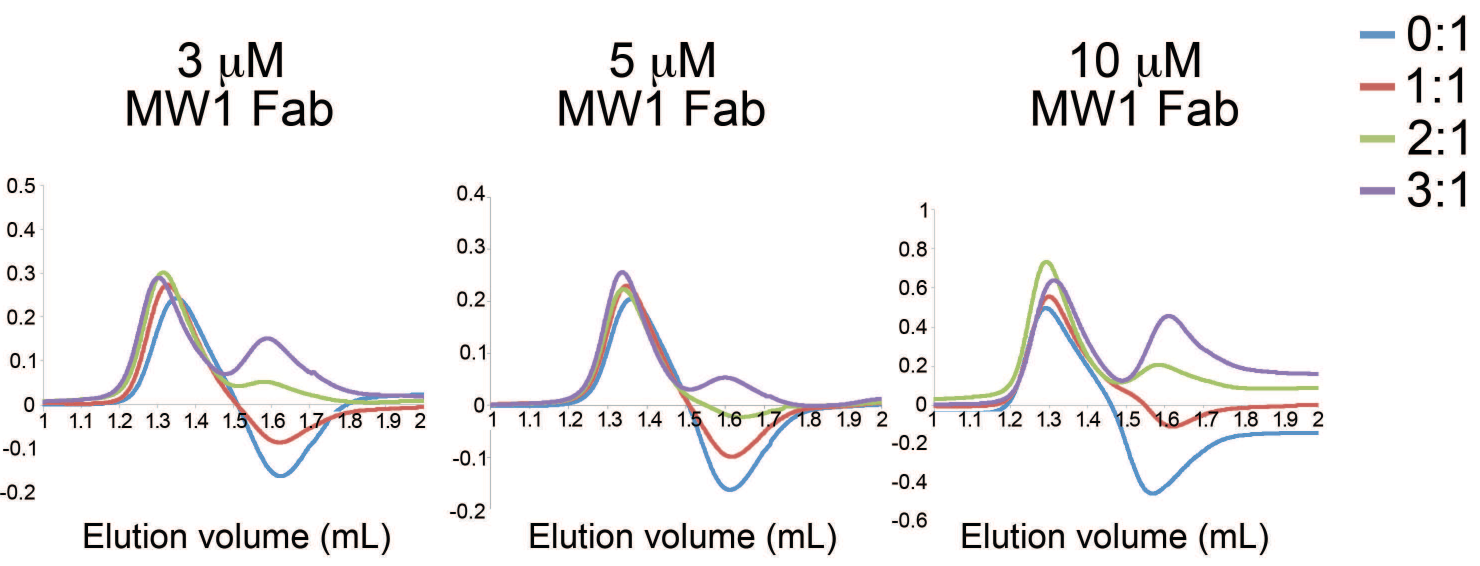

Figure 4 
(a)

(b)
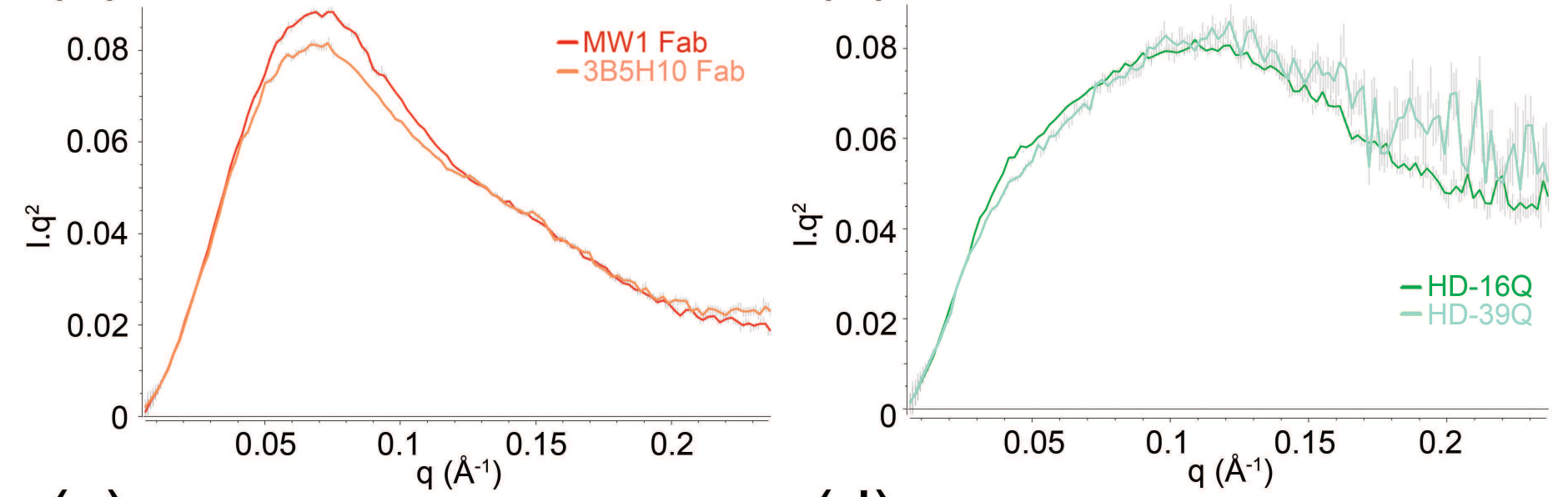

(c)

(d)
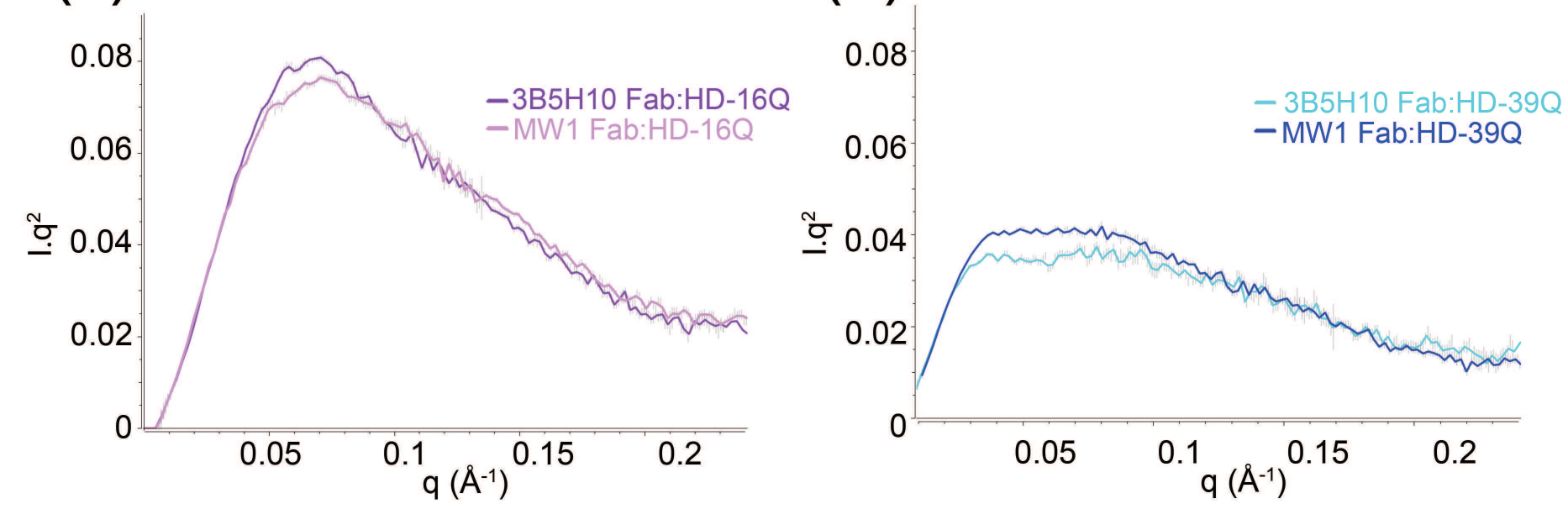

Figure 5 
(a)
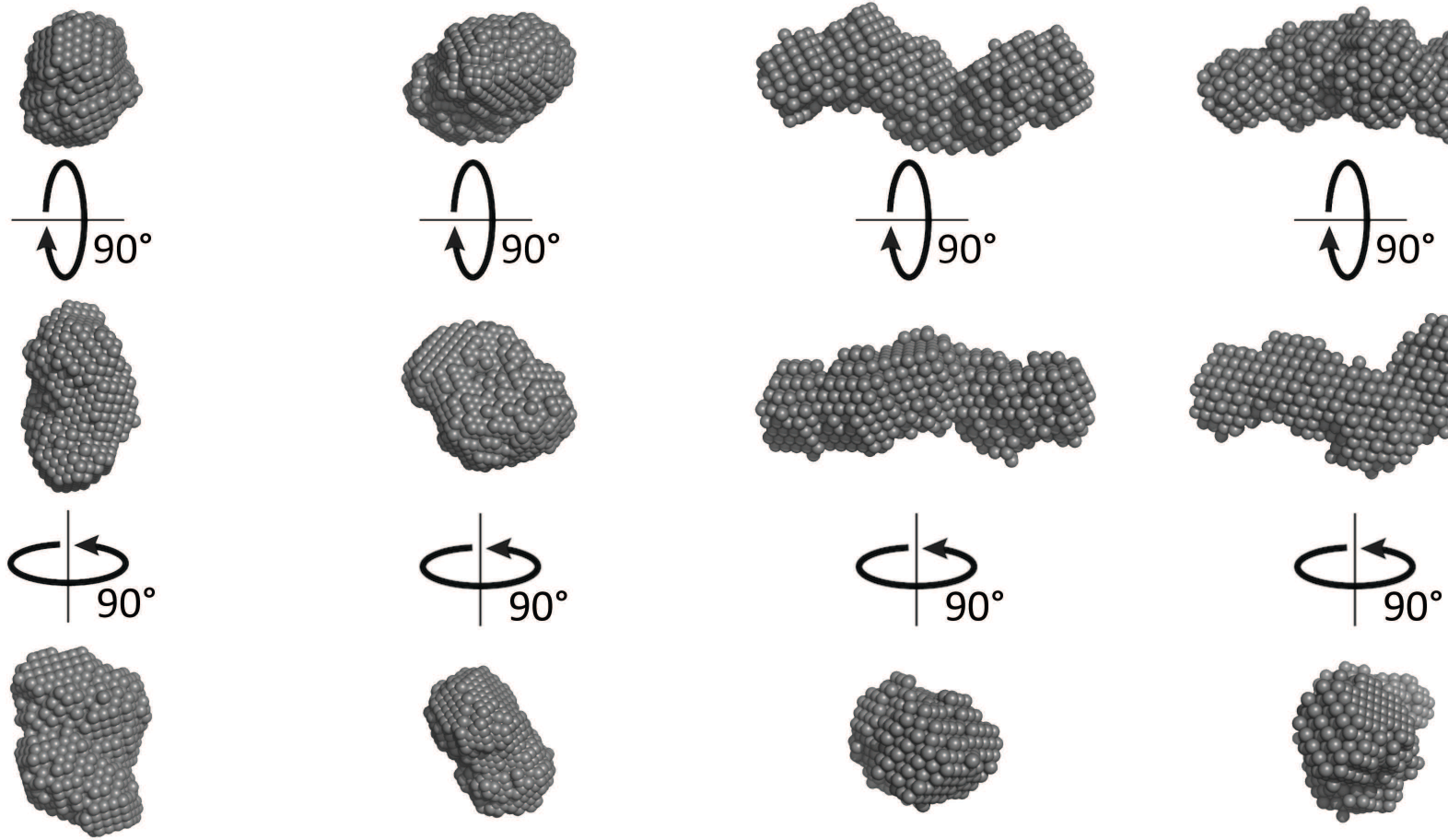

3B5H10 Fab

MW1 Fab

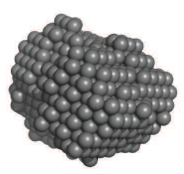

HD-16Q

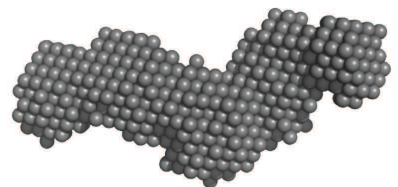

(b)
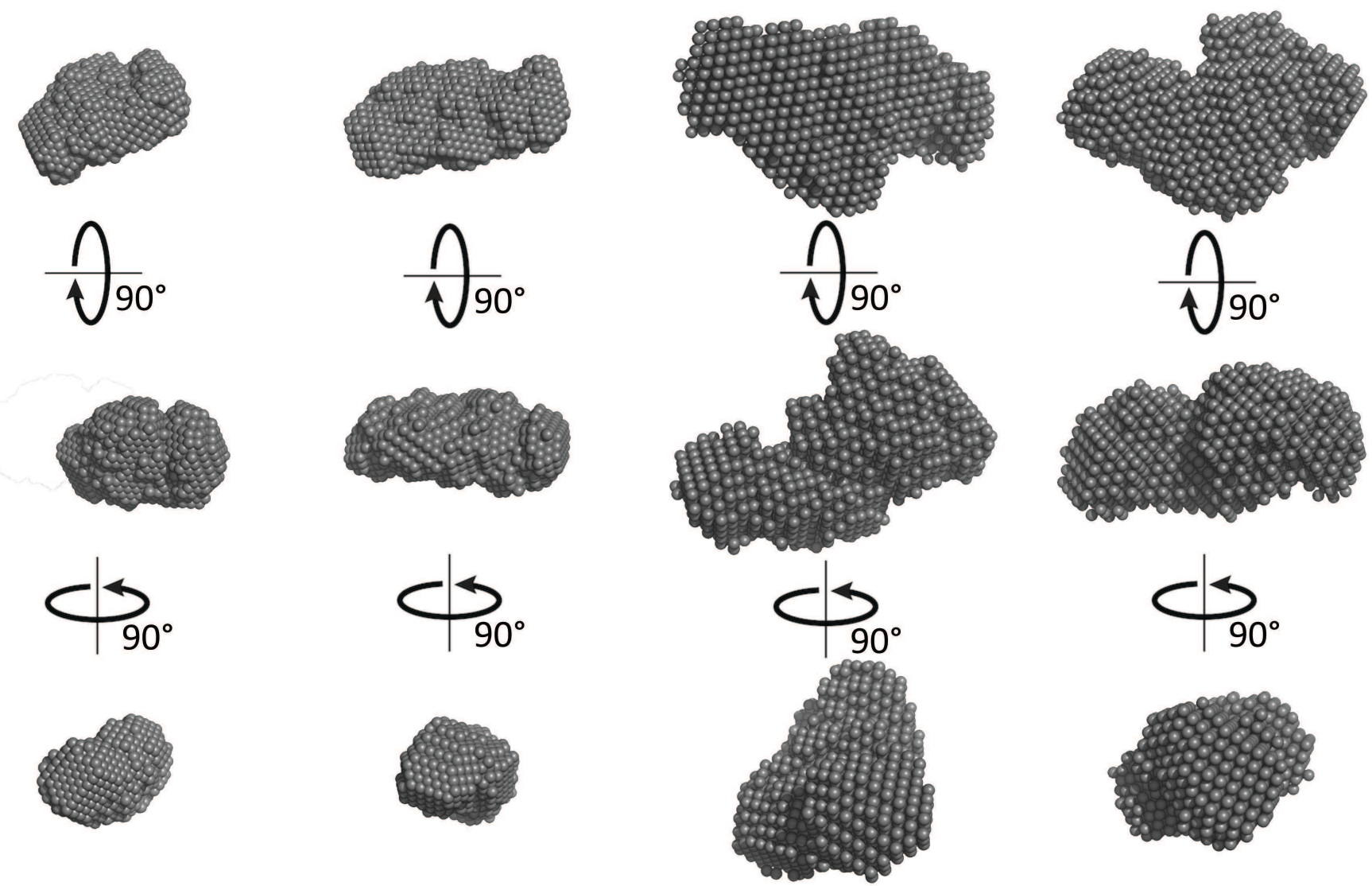

3B5H10

MW1

Fab:HD-16Q

Fab:HD-16Q

3B5H10

Fab:HD-39Q
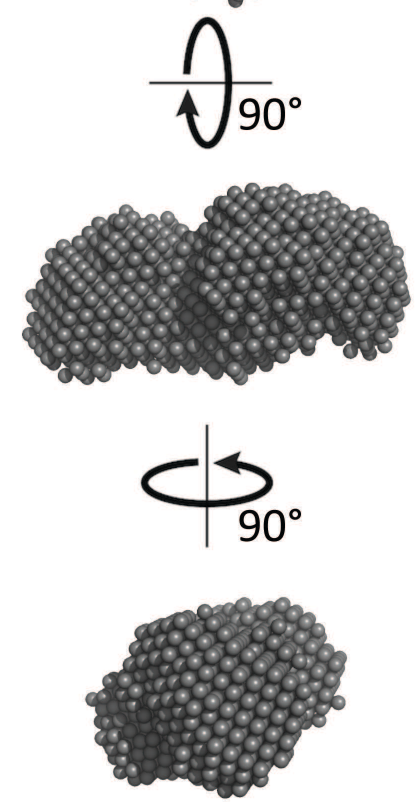

MW1

Fab:HD-39Q

Figure 6 